\title{
Quality of health care and patient safety in extreme adversity settings in the Eastern Mediterranean Region: a qualitative multicountry assessment
}

\author{
Mondher Letaief, ${ }^{1}$ Sheila Leatherman, ${ }^{2}$ Linda Tawfik, ${ }^{3}$ Ahmed Alboksmaty, ${ }^{4}$ Matthew Neilson ${ }^{5}$ and Dirk Horemans ${ }^{6}$
}

${ }^{1}$ Department of Health System Development, World Health Organization, Regional Office for the Eastern Mediterranean, Cairo, Egypt. ${ }^{2}$ Gillings School of Global Public Health, University of North Carolina at Chapel Hill, Chapel Hill, North Carolina, United States of America. ${ }^{3}$ WHO Collaborating Centre for Evidence Research for Sexual and Reproductive Health, University of North Carolina at Chapel Hill, Chapel Hill, United States of America. ${ }^{4}$ Department of Health System Development, World Health Organization, Regional Office for the Eastern Mediterranean, Cairo, Egypt. ${ }^{5}$ Department of Service Delivery \& Safety, World Health Organization, Geneva, Switzerland. ${ }^{6}$ Department of Integrated Health Services, World Health Organization, Geneva, Switzerland. (Correspondence to: Mondher Letaief: letaiefm@who.int).

\begin{abstract}
Background: Quality and patient safety are essential for the provision of effective health care services. Research on these aspects is lacking in settings of extreme adversity.

Aims: This study aimed to explore the perception of health care stakeholders working in extreme adversity settings of the quality of health care and patient safety.

Methods: This was a qualitative study conducted through semistructured interviews with 26 health care stakeholders from seven countries of the World Health Organization's Eastern Mediterranean Region which are experiencing emergencies. The interviews explored the respondents' perspectives of four aspects of quality and patient safety: definition of the quality of health care, challenges to the provision of good quality health care in emergency settings, priority health services and populations in emergency settings, and interventions to improve health care quality and patient safety.

Results: The participants emphasized that saving lives was the main priority in extreme adversity settings. While all people living in emergency situations were vulnerable and at risk, the respondents considered women and children, poor and disabled people, and those living in hard-to-reach areas the priority populations to be targeted by improvement interventions. The challenges to quality of health care were: financing problems, service inaccessibility, insecurity of health workers, break down in health systems, and inadequate infrastructure. Respondents proposed interventions to improve quality, however, their effective implementation remains challenging in these exceptional settings.
\end{abstract}

Conclusions: The interventions identified can serve as a basis for improvements in health care quality that could be adapted to extreme adversity settings.

Keywords: emergencies, quality of health care, quality improvement, health personnel, Eastern Mediterranean region

Citation: Letaief M; Leatherman S; Tawfik L; Alboksmaty A; Neilson M; Horemans D. Quality of health care and patient safety in extreme adversity settings in the Eastern Mediterranean Region: a qualitative multicountry assessment. East Mediterr Health J. 2021;27(2):167-176. https://doi. org/10.26719/2021.27.2.167

Received: 29/01/20; accepted: 21/06/20

Copyright (C) World Health Organization (WHO) 2021. Open Access. Some rights reserved. This work is available under the CC BY-NC-SA 3.0 IGO license (https://creativecommons.org/licenses/by-nc-sa/3.o/igo)

\section{Introduction}

Good quality health care is a priority according to global health institutions. The Sustainable Development Goals demand more than just expanded access to care to attain universal health coverage (UHC) (1). In response, the World Health Organization (WHO) launched the national quality policy and strategy as a comprehensive tool that includes stepwise guidance on how to successfully develop and implement specific strategies and interventions that would ensure improved health system capacity for quality and patient safety (2).

Furthermore, WHO's Thirteenth General Programme of Work (GPW-13) has indicated the important need to address quality and patient safety in emergency settings to achieve the Organization's proposed strategic priorities (3). This was emphasized in a resolution of the 71st World Health Assembly in 2018 that set the targets: (i) one billion more people to benefit from UHC and (ii) one billion more people better protected from health emergencies (3). These targets, together with the strategies needed to achieve them, are included in Vision 2023, the roadmap of the WHO Regional Director for the Eastern Mediterranean to enhance progress in providing good quality health care services for all (4).

Alarming numbers of people live in extreme adversity all over the world and these numbers are increasing each year. In 2019, 131.7 million people worldwide were in need of humanitarian aid, and 1 in every 70 people was living in crisis settings such as escalating conflicts, economic hardship and food insecurity. A lack of research in this area has made it difficult to develop appropriate interventions to improve health care quality in these environments (5).

Extreme adversity settings include fragile, unstable states that are affected by acute or ongoing political 
turmoil, conflicts and natural disasters where there is a breakdown in authority, governance systems, and services. Many of the countries of the WHO Eastern Mediterranean Region are experiencing such extreme adversity (6). In September 2018, eight of the 22 countries of the Region were experiencing 10 graded emergencies, based on the WHO grading system of emergencies, affecting over 71 million people $(5,7)$.

In emergency settings, it is challenging to provide good quality health care and identify the main challenges to improving care at the national level. Health care professionals' definition of good quality health care and patient safety vary, particularly during emergencies $(8,9)$. Substantial difficulties during emergencies impede the provision of good quality and safe health care services (10). For example, due to the war in Yemen, only $45 \%$ of health care facilities are still functioning (11). Growing attention is now being paid to developing innovative and practical tools to tackle these challenges and ensure an attainable level of quality and safety in health care services, even during emergencies $(10,12)$.

In view of the pressing need to address the challenges of health care quality in emergencies and identify means of improving care in these settings, the WHO Regional Office for the Eastern Mediterranean, in collaboration with the University of North Carolina, conducted a qualitative assessment to identify these challenges and explore interventions for quality improvement in extreme adversity settings. The objectives were to:

- Understand the perception of health professionals working in fragile, conflict-affected and vulnerable setting of the quality of health care, in terms of (i): the meaning of quality; (ii) the main challenges to provision of good quality health care in acute and protracted emergencies; (iii) the approaches, methods and tools used or needed to overcome these challenges; and (iv) the type of support and guidance needed to measure and improve quality of care.

- Provide an evidence base for the development of an action framework to promote health care quality in fragile, conflict-affected and vulnerable settings.

\section{Methods}

\section{Study settings and sample}

As of September 2018, eight countries in the Region were experiencing different grades of emergencies, according to WHO's grading $(13,14)$. We included two of three countries with grade 3 emergencies (Syrian Arab Republic and Yemen), three of four countries with grade 2 emergencies (Iraq, Libya, and Palestine) and one of the two countries with a grade 1 emergency (Afghanistan). In addition, Lebanon was included as a representative country for countries indirectly affected by emergencies (because of the arrival of refugees).

These countries vary in terms of: the degree of fragility of their health systems; the stage of emergency, from acute to protracted; and the need to improve the quality of health care services. These differences allow comparison between these settings and stable countries regarding the definition of health care quality, challenges to providing good quality care and potential interventions to improve care.

The inclusion criteria for selecting respondents were: (i) works in the health emergency response in a public or private health facility as a policy-maker, manager or director of a health department or facility, clinical provider (doctor or nurse), representative of a nongovernmental organization (NGO), academician, or a WHO focal point in one of the countries; (ii) consents to the online interview being recorded during the data collection period, April-November, 2018; and (iii) speaks Arabic or English.

\section{Data collection}

We initially contacted 32 candidates in the six selected countries to request a phone or an online interview. A key informant interview guide was developed, pilot-tested with two respondents in the regional office, and adjusted accordingly. Of the 32 people contacted, 24 responded and consented to be interviewed between April and November 2018.

We asked each respondent four key questions.

- What is the meaning of quality in your organization or setting?

- What are the biggest challenges faced by your organization in this time of crisis?

- What approaches, methods and tools does your organization use to overcome these challenges?

- What support and guidance are needed to reliably measure and improve quality of care?

The study coordinator conducted semistructured interviews in Arabic or English, depending on the respondent's language proficiency and preference. The interviewer encouraged respondents to elaborate on their responses and to decide on priority populations and priority medical conditions from their perspectives.

Of the 24 respondents, three were from Afghanistan, three from Iraq, four from Lebanon, one from Libya, three from Palestine, three from the Syrian Arab Republic, seven from Yemen, as well the two respondents in the pilot study from the regional office. To validate and further explore the initial findings, we conducted four follow-up, face-to-face interviews with participants from Yemen who were visiting the WHO Regional Office in Cairo. In the follow-up interviews, we asked the respondents if there were additional interventions for quality improvement they could propose, what their top recommendations for quality improvement were, and who the key decision-makers were on provision of health care service.

\section{Data analysis}

We applied a thematic approach to the analysis of the data collected to ascertain what themes emerged and 
determine to what extent they aligned with the types of quality interventions in the WHO Handbook for national quality policy and strategy (15). The taped interviews were transcribed and translated into English, as needed. We reviewed the data, coded the themes identified and categorized the responses into: challenges to quality and safety of health care services, approaches to improve quality and safety, methods, tools, and support needed in order to make improvements.

We also prepared one-page summaries of the transcripts. The summaries highlighted the main messages arising from the definitions of quality the respondents gave, the challenges to provision of good quality health care that they highlighted, and the key approaches, methods and recommended tools they proposed for improving quality of care in their respective settings.

For quality control, one investigator coded a sample of transcripts using emic (from the perspective of interviewees) and etic (from the perspective of external observers) terms, ensuring that the one-page documents accurately summarized the key information from the transcripts. The research team at the regional office and the University of North Carolina, regularly reviewed the transcripts and summaries to synthesize results. We compiled final lists of quality-related challenges and interventions, as stated by participants.

We analysed and synthesized the data as follows: (i) themed quotes emerging from each research question; (ii) priority populations and medical needs; and (iii) categorization of responses by theme.

\section{Ethical considerations}

This study is considered as a service evaluation, with no disruption or changing interventions to the regular provided health care services within the participating countries. Therefore, formal ethical approval was deemed unnecessary. However, we assured respondents of the confidentiality and anonymity of their information and obtained their verbal consent to participate.

\section{Results}

\section{Definition of quality}

Respondents working in extreme adversity settings have a unique perspective to add to the usual definitions of health care quality. In acute emergency settings, the definition of quality highlights saving lives as the main priority, regardless of the quality of care. The standard definitions of health care quality also emphasize doing no harm while providing health care services in most efficient ways.

"We don't have control over the staff to work according to protocols, guidelines and procedures...they seem to become less of a priority when it comes to saving lives." (respondent from Palestine)
"Quality in war relies on reducing the number of deaths and handicaps that we see in such times." (respondent from Syrian Arab Republic)

\section{Priority populations and medical conditions}

Public health interventions should be prioritized based on demographic, epidemiological and ethical factors. When asked about populations in greatest need of health care in emergency settings, the respondents suggested women and children, specifically pregnant women and newborns, as well as poor people, disabled people, and people living in remote or difficult-to-reach areas (Table 1).

"During such hardships, all people are exposed to poor quality services, but due to circumstances, women and children are the most vulnerable because men have more mobility and flexibility." (respondent from Yemen)

The health care service priorities during emergencies cited by the respondents matched those in stable countries (Table 1), i.e. communicable and noncommunicable diseases as well as health services to women and children. However, war-related conditions were frequently mentioned, such as burns and trauma.

"When many people are injured, not all hospitals can handle the burden" (respondent from Iraq)

\section{Challenges}

The challenges of providing good quality health care during emergencies reported by the respondents included: health financing and resources issues; inaccessibility of services; inadequate infrastructure; health system breakdown (human resources, medicines and supplies, information governance, and referral systems); and disregard of quality of care protocols. Table 2 shows the quality and safety challenges identified by the respondents.

Table 1 Priority populations and medical condition identified by the respondents by greatest need, from the respondents' perspective

\begin{tabular}{ll}
\hline Category & \multicolumn{1}{c}{ Priorities } \\
\hline Populations & Women and children (under 12 years) \\
& Pregnant women and newborns \\
& Poor people \\
& Remote and difficult-to-reach communities \\
& Disabled people \\
& People affected by gender discrimination \\
Medical conditions & Communicable diseases \\
& Noncommunicable diseases \\
& Neurological conditions \\
& Trauma and war-related injuries including \\
& amputations \\
& Mental health \\
& Elective surgery \\
& Burns and chemical injuries \\
& Infections \\
\hline
\end{tabular}




\begin{tabular}{|c|c|}
\hline Types of challenges & Specific challenges \\
\hline Lack of resources & $\begin{array}{l}\text { Equipment shortages } \\
\text { Medicine shortages } \\
\text { Lack of medical devices } \\
\text { Lack of blood products } \\
\text { Insufficient number of staffed beds } \\
\text { Lack of specialized units }\end{array}$ \\
\hline Problems of access for patients & $\begin{array}{l}\text { Unsafe environment for patients and health workers } \\
\text { Unreliable access } \\
\text { Remote, hard-to-reach areas } \\
\text { General safety and security concerns } \\
\text { Inadequate and unreliable transportation }\end{array}$ \\
\hline Infrastructure inadequacies & $\begin{array}{l}\text { Old, damaged and destroyed facilities } \\
\text { Limited clean water supply } \\
\text { Unreliable electricity suppliers } \\
\text { Water, sanitation and hygiene (WASH) challenges } \\
\text { Unreliable internet and/or means of communication } \\
\text { Damaged roads and lack of fuel }\end{array}$ \\
\hline Health information deficiencies & $\begin{array}{l}\text { Paper-based records and/or unreliable electronic health records } \\
\text { Incomplete and unreliable data } \\
\text { No systematic sharing of data between facilities } \\
\text { Data collected but not used for decision-making } \\
\text { Lack of evidence-based action planning } \\
\text { Little or no safety and quality measurements }\end{array}$ \\
\hline Health financing issues & $\begin{array}{l}\text { Dependence on donors } \\
\text { Inadequate funds for infrastructure, salaries and supplies } \\
\text { Inadequate and/or unreliable payment of staff salaries or compensation } \\
\text { Lack of a budget for training } \\
\text { Insufficient numbers of skilled doctors, nurses and workers }\end{array}$ \\
\hline Human resource and workforce deficiencies & $\begin{array}{l}\text { Lack specialists, e.g. anaesthetists, intensive care specialists, neurosurgeons } \\
\text { Difficulty in retaining motivated and skilled staff } \\
\text { Constant movement and/or migration of health workers } \\
\text { Inadequate training } \\
\text { Lack of preparedness plans at the national level }\end{array}$ \\
\hline Health system challenges & $\begin{array}{l}\text { Lack of a culture of safety and quality } \\
\text { Lack of standards and protocols in a conflict context } \\
\text { Lack enabling laws, regulations or national strategies } \\
\text { Inadequate safety and/or quality programmes in health facilities } \\
\text { High incidence of infections (especially surgical site infections) } \\
\text { Poorly functioning referral systems }\end{array}$ \\
\hline
\end{tabular}

"Our health provision is mainly donor dependent, so that if today we do not have that donor support, it might collapse completely." (respondent from Afghanistan) “...insufficiency of human resources and medical devices, [no] safety protocols or patient referral system. Most of the infrastructure is destroyed due to the war" (respondent from Syrian Arab Republic)

\section{Interventions}

The interventions proposed by the respondents to promote quality of health care in emergency situations in practice are summarized in Table 3. 


\begin{tabular}{|c|c|}
\hline Type of challenge & Adaptive strategies (in use or proposed) \\
\hline \multirow[t]{3}{*}{ Lack of resources } & Rely on donors to fund services \\
\hline & Rely on donors to pay for and/or supply essential medicines \\
\hline & Reassign private vehicles to transfer patients and use transportation of NGOs \\
\hline \multirow[t]{8}{*}{ Problems of access for patients } & Define and adopt an essential health services package \\
\hline & $\begin{array}{l}\text { Make agreements with the private sector and/or NGOs for security, coverage, distribution of } \\
\text { supplies }\end{array}$ \\
\hline & Develop protocols for security within health facilities \\
\hline & Operationalize mobile facilities and clinics \\
\hline & $\mathrm{MoH}$ contracts for NGOs \\
\hline & Use tents for emergency wards, triage and chemical treatment \\
\hline & Implement special programmes, e.g. neonatal care for refugees \\
\hline & Devise ways to attract private-sector providers \\
\hline Infrastructure inadequacies & Develop back-up plans for water and power \\
\hline Health information deficiencies & Assigned governance body to provide annual reports on population health status \\
\hline \multirow[t]{3}{*}{ Health financing issues } & Negotiate for hospital costs to be paid by WHO or NGOs \\
\hline & Negotiate with WHO and/or NGOs to pay salaries \\
\hline & Implement user fees for additional revenue \\
\hline \multirow[t]{3}{*}{ Human resources and workforce deficiencies } & $\begin{array}{l}\text { Technical capacity building of health care professionals to be prepared to respond in cases of } \\
\text { emergencies }\end{array}$ \\
\hline & Contract with NGOs to do training for health care professionals as needed \\
\hline & Train all appropriate personnel for emergency response \\
\hline \multirow[t]{8}{*}{ Health system challenges } & $\mathrm{MoH}$ is to use external surveyors to evaluate its health facilities \\
\hline & Have $\mathrm{MoH}$ emergency assessment and response tools in health facilities \\
\hline & Perform simulations to assess disaster response and hold debriefings \\
\hline & Use the WHO surgery safety checklist \\
\hline & Use assessments by external organizations, health partners and hotlines \\
\hline & Develop protocols for medicine administration in emergencies \\
\hline & Institute adverse event reporting \\
\hline & Institute quality reporting through scorecards \\
\hline
\end{tabular}

NGOs= nongovernmental organizations; $\mathrm{MoH}=$ ministry of health; $\mathrm{WHO}=$ World Health Organization

"...[we need] practical implementation addressing infrastructure, equipment shortages, HR and...service provision..." (respondent from Palestine)

"We are focusing on strengthening the health system, because...sometimes [the problem] is the efficiency of using the resources." (respondent from Libya)

\section{Validation by Yemeni respondents}

The validation interviews with four respondents from Yemen indicated the need for strategies to: ensure a minimum basic health services package; mobilize international humanitarian groups to increase funding; ensure that health facilities are prepared for provision of 24-hour services at every level; increase the capacity of health authorities and district health offices; address shortages in human resources; and assess gaps in health care services.

\section{Summary of interventions}

Addressing quality of care in extreme adversity settings requires coordinated interventions at all health care levels to: provide access to health services; qualify an envi- ronment for health systems to function; reduce harm; improve clinical care; and engage patients, families and communities. The proposed list of interventions identified by our respondents (Table 4) serves as a basis for designing and implementing improvement interventions adapted to emergency contexts.

Our results also suggest that a minimum basic services package, based on disease burden, risk factors and the cost-effectiveness of interventions, should be provided to health sector stakeholders, including health care professionals, managers, policy-makers, and others, with quality as a cornerstone. The package ensures access to services across eight key health care components: general services and trauma care, reproductive, maternal and newborn health, child health, mental health and psychosocial support, nutrition, noncommunicable diseases, communicable diseases and environmental health. 


\begin{tabular}{|c|c|}
\hline Category & Interventions or actions \\
\hline \multirow[t]{6}{*}{ Ensuring access and basic infrastructure } & Defined minimum health services package with quality standards \\
\hline & Better management of supplies, medicines, equipment, procurement and placement \\
\hline & Coordination platform for all health care facilities at different levels of care \\
\hline & Health information system for patient care, and quality and safety issues \\
\hline & More public-private partnerships \\
\hline & $\begin{array}{l}\text { Better access for refugees without health coverage to private (paying) care through UNHCR or other } \\
\text { entities }\end{array}$ \\
\hline \multirow[t]{3}{*}{ Enabling system environment } & National guidelines and protocols \\
\hline & Quality teams or units in all facilities and organizations \\
\hline & External expert training on quality (including use of data) \\
\hline \multirow[t]{4}{*}{ Reducing harm to patients } & Development of a safety culture \\
\hline & Elimination of medical errors \\
\hline & Support of infection prevention and control programmes in hospitals, including training by WHO \\
\hline & Use of WHO tools for surgical safety and infection control \\
\hline \multirow[t]{8}{*}{ Improving clinical care } & Use of mobile clinics and facilities \\
\hline & Engagement of NGOs and other private-sector bodies for provision of health services \\
\hline & Establishment of mental health and rehabilitation programmes for people with war injuries \\
\hline & $\begin{array}{l}\text { Assessment of the effect of quality tools and methods, such as surgical safety checklists and } \\
\text { scorecards }\end{array}$ \\
\hline & Use of external surveys and assessments of facilities to monitor quality and safety \\
\hline & Development of tools and methods to efficiently share data between facilities \\
\hline & Provision of timely reports at all levels in emergencies \\
\hline & $\begin{array}{l}\text { Inspection of health care professional licensing from relevant authorities, and adherence to clinical } \\
\text { guidelines by health care professionals }\end{array}$ \\
\hline $\begin{array}{l}\text { Engaging patients, families and } \\
\text { communities }\end{array}$ & Improvement of communications with patients and awareness of their rights \\
\hline \multirow{4}{*}{$\begin{array}{l}\text { Other responses related to global standards } \\
\text { of quality }\end{array}$} & Development of a guide for quality of health services in emergencies by WHO \\
\hline & $\begin{array}{l}\text { Development of minimum quality standards, tools and frameworks, and provision of support to } \\
\text { ensure sustainability of resources, e.g. supplies and medicines }\end{array}$ \\
\hline & Assistance of WHO to develop emergency assessment and response mechanisms \\
\hline & $\begin{array}{l}\text { Development of an emergency control programme within the health ministry for resource } \\
\text { mobilization during emergencies and monitoring of an accreditation programme }\end{array}$ \\
\hline
\end{tabular}

UNHCR= United Nations High Commissioner for Refugees; $\mathrm{WHO}=$ World Health Organization; $\mathrm{NGO}=$ = nongovernmental organizations.

\section{Discussion}

The design and implementation of interventions often require an analysis of possible implementation challenges, and identification of priorities, feasibility of interventions and resource needs (16). In stable countries, governments can set policies and standards on quality, and enforce them through regulations, legislation and licensing of providers. If a country in extreme adversity is fragmented with disparate state and non-state actors, health policy-makers and all relevant stakeholders, such as frontline health care professionals and health workers, should be able to at least implement some interventions to improve quality in priority areas, such as a basic health service package, clinical protocols, or licensing and certifying of health workers. Adapting and contextualizing interventions according to each country's setting would lead to effective implementation and could be a key for success (17).
Our results highlight the importance of fostering people-centred care in the exceptional circumstances faced during emergencies and crises. All populations suffer in war, but women and children were priority groups identified by our respondents, which is supported by figures of their reported high death rates during emergencies $(18,19)$. Our respondents reported a broad range of challenges that impede the establishment of an efficient health system, which is consistent with previous literature $(20,21)$. These challenges include: geopolitical issues; lack of funding, human resources and medical supplies; security problems; and water, sanitation and hygiene issues (22). The lack of existing emergency plans for actual field conditions in crises suggests a need to tailor policies and strategies to each country's situation.

Health care innovation was indirectly mentioned as a way to improve quality and safety of health care services in extreme adversity settings, such as mobile clinics, advanced communication tools and modern health 
information technologies. International and national collaboration is required to further study and adapt innovative interventions to improve the quality of health care and patient safety in emergency settings (23).

Our study also suggests that the definition of quality differs in acute and protracted emergency situations compared with stable contexts. For example, the global health literature highlights six domains of health care quality: effectiveness, patient-centeredness, timeliness, efficiency, equity and safety $(24,25)$. In acute emergencies (e.g. Iraq, Syrian Arab Republic and Yemen), our respondents defined quality based on health care accessibility, safety and security, clinical guidelines, human resources and referral systems. The quality dimensions may be fundamentally similar, but these dimensions might need to be adapted and prioritized based on the specific circumstances during emergencies.

In contrast, in more protracted emergencies (Afghanistan, Lebanon, Libya and Palestine), themes on quality focused on health care financing, security, gaps in community engagement, planning for quality, and monitoring and evaluation. The literature defines quality of health care in terms of care that improves population health and well-being (26), while in acute emergencies, the definition for quality is fundamental and sad - "health care services which aim to save lives regardless of the quality of care".

Our study identified some distinctive challenges and gaps in providing good quality health care in extreme adversity settings. However, there have been some unusual findings; for example, in Yemen, given the magnitude of malnutrition during the crisis (27), prioritization or treatment of malnutrition as a quality intervention was notmuch mentioned byour respondents, which was surprising. Other quality measures that were underemphasized during the interviews were emergency preparedness, the private sector's role, gender inequality, accountability of different actors to health care services, patient safety measures, and the value of community engagement. These underemphasized measures should be an avenue for further research to explore reasons behind that in emergency contexts. The views of our respondents differed on elimination of the causes of human error during clinical practice, facilitybased infection control measures and the safety of health care workers.

Of the determinants of quality of health care, the security and personal safety of medical teams working in emergencies was emphasized as a major gap from the interviewees' perspective. This finding is consistent with other studies that showed unsafe working environments were a reason for health workers suspending services in countries affected by crises $(28,29)$. Another factor that our respondents did not really highlight was the role of community engagement; however, a previous study illustrated that patient engagement can have a significant impact on improving the quality of health care (30). Furthermore, engaging the private sector (31) and involving primary health care services (32) were also found to have a positive influence on quality of care and patient safety.

Our study engaged international, regional, national and local experts to explore an increasingly important but difficult aspect of quality of care research, especially in emergency settings, and responded to a clear gap in the research. Our study has some limitations which are largely due to the nature of the data collection, as it was not possible to cost-effectively and safely conduct face-to-face interviews in many of the settings where our respondent were working. Poor communication networks and internet connectivity issues hampered the interviews. Although confidentiality and anonymity of information were ensured, and consent was obtained from the participants, the sensitivity of some questions resulted in several respondents being noticeably reluctant to elaborate on their responses, although others freely expressed their views. Lastly, knowledge about quality of care varied considerably among the respondents.

Evidence-based quality interventions must be selected, adapted to the context and implemented based on the phases of a crisis (33). In the emergency phase, interventions may simply focus on establishing access to care and a basic minimum services package. In the transitional phase, when a country tries to move from an emergency to a recovery state, the focus shifts from relief to more long-term strategies, while the post-crisis phase entails health system strengthening and integration (34). Stakeholders at various levels of the health system have a role in the selection, implementation, monitoring and evaluation of interventions, and these roles need to be well-defined and coordinated across the health sector (33,35).

Our respondents proposed short- and long-term strategies to provide the best quality services applicable to the context. These interventions now need to be tested at the operational level, with continuous monitoring and evaluation. While the challenges differ, enforcing quality standards is a starting point for improving health status and rebuilding communities (36). It is to be hoped that implementation of these interventions will shift the focus from just saving lives to consideration of the quality of health care services in terms of safety, effectiveness, patient-centeredness, timeliness, efficiency and equity.

Funding: ML and DH receive salary support as employees of WHO; AA and MN work as consultants for WHO and conducting the study was one of their responsibilities; and SL and LT receive support from the University of North Carolina at Chapel Hill, USA. No external funding was received for this study. The views expressed in this study are those of the authors, based on the participants' perspective, and are not necessarily those of the entities the authors are affiliated with and/or supported by.

Competing interests: None declared. 


\section{Qualité des soins de santé et sécurité des patients dans des contextes d'extrême adversité dans la Région de la Méditerranée orientale : évaluation qualitative multipays}

\section{Résumé}

Contexte : La qualité des soins et la sécurité des patients sont essentielles pour la prestation de services de soins de santé efficaces. La recherche sur ces aspects fait défaut dans les cont extes d'extrême adversité.

Objectifs : La présente étude visait à examiner la perception des intervenants en soins de santé qui travaillent dans des situations d'extrême adversité pour ce qui concerne la qualité des soins de santé et la sécurité des patients.

Méthodes : Il s'agissait d'une étude qualitative réalisée dans le cadre d'entretiens semi-structurés avec 26 parties prenantes du secteur des soins de santé de sept pays de la Région de la Méditerranée orientale de l'Organisation mondiale de la Santé confrontés à des situations d'urgence. Les entretiens ont examiné le point de vue des répondants sur quatre aspects de la qualité des soins et de la sécurité des patients : la définition de la qualité des soins de santé, les obstacles à la prestation de soins de santé de qualité dans les situations d'urgence, les services de santé prioritaires et les populations vivant dans des situations d'urgence, et les interventions visant à améliorer la qualité des soins de santé et la sécurité des patients.

Résultats: Les participants ont souligné le fait que sauver des vies était la principale priorité dans les situations d'extrême adversité. Si toutes les personnes vivant en situation d'urgence étaient vulnérables et à risque, les répondants considéraient que les femmes et les enfants, les personnes pauvres et handicapées et les personnes vivant dans des zones difficiles d'accès étaient les populations prioritaires à cibler par les interventions d'amélioration. Les défis à relever pour ce qui est de la qualité des soins de santé sont les suivants : problèmes de financement, inaccessibilité des services, insécurité des agents de santé, effondrement des systèmes de santé et insuffisance des infrastructures. Les répondants ont proposé des interventions pour améliorer la qualité, mais leur mise en œuvre efficace reste difficile dans ces contextes exceptionnels.

Conclusions : Les interventions identifiées peuvent servir de base à des améliorations de la qualité des soins de santé qui pourraient être adaptées à des contextes d'extrême adversité.

$$
\text { منذر لطوة الرعاية الصحية وسلامة المرضى في المناطق التي تو اجه محناً شديدة في إقليم شرق المتوسط: تقييم وصفي متعدد }
$$

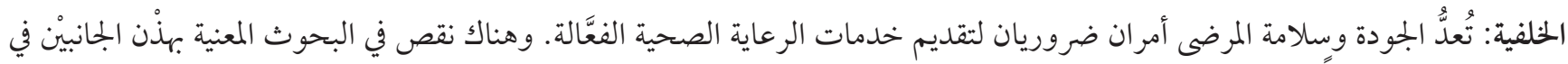

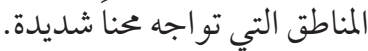

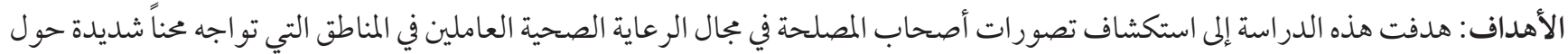
جودة الرعاية الصحية وسلامة مدافه المرضى.

طرق البحث: كانت الدر اسة وصفية وتخللتها مقابلات شبه منظمة مع 26 من أصحاب المصلحة في مجال الرعاية الصحية من سبعة بلدان في إقليم

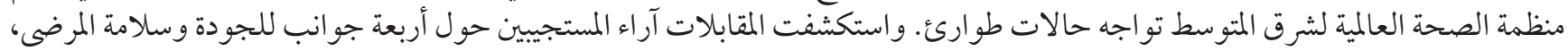

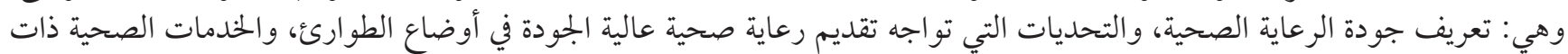

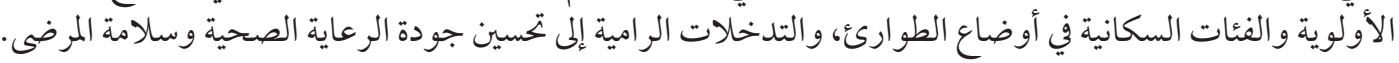

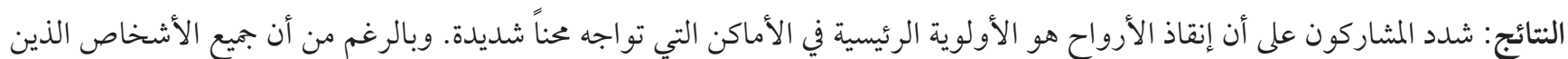

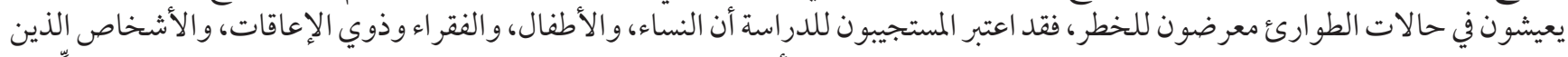

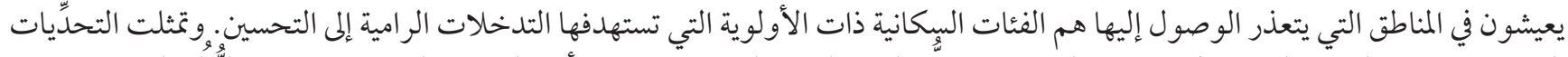

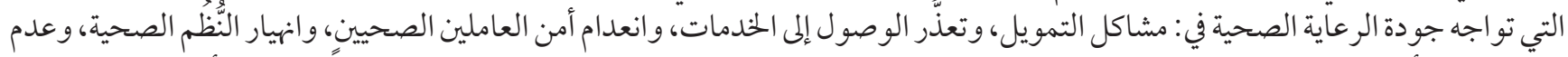

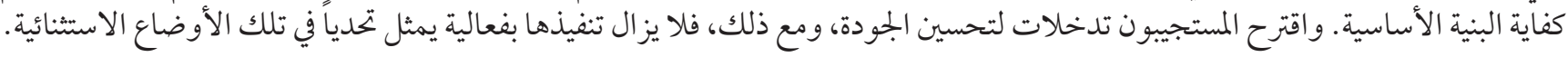
الاستنتاجات: يمكن أن تكون التدخلات التي حددها المستجيبون بمثابة أساس لأنشطة تحسين جودة الرعاية الصحية والتي يمكن تكييفها مع المناطق التي بها محن شديدة. 


\section{References}

1. Kruk ME, Gage AD, Joseph NT, Danaei G, García-Saisó S, Salomon JA. Mortality due to low-quality health systems in the universal health coverage era: a systematic analysis of amenable deaths in 137 countries. Lancet. 2018;392(10160):2203-12. https://doi. org/10.1016/So140-6736(18)31668-4

2. Handbook for national quality policy and strategy: a practical approach for developing policy and strategy to improve quality of care. Geneva: World Health Organization; 2018 (https://www.who.int/servicedeliverysafety/areas/qhc/nqps_handbook/en/, accessed 15 May 2019).

3. Thirteenth General Programme of Work 2019-2023: promote health, keep the world safe, serve the vulnerable. Geneva: World Health Organization; 2018 (https://apps.who.int/iris/bitstream/handle/10665/324775/WHO-PRP-18.1-eng.pdf, accessed: 15 May 2019).

4. Vision 2023. Eastern Mediterranean Region. Cairo: World Health Organization Regional Office for the Eastern Mediterranean; 2018 (http://www.emro.who.int/about-who/vision2023/vision-2023.html, accessed 13 February 2019).

5. Global Humanitarian Overview 2019. Geneva: United Nations Office for the Coordination of Humanitarian Affairs; 2018 (https:// www.unocha.org/global-humanitarian-overview-2019, accessed 5 June, 2019).

6. Buliva E, Elhakim M, Tran Minh NN, Elkholy A, Mala P, Abubakar A, et al. Emerging and re-emerging diseases in the World Health Organization (WHO) Eastern Mediterranean Region - progress, challenges, and WHO initiatives. Front Public Health. 2017;5:276. https://doi.org/10.3389/fpubh.2017.00276

7. Report on primary health care in the Eastern Mediterranean Region: review of progress over the last decade (2008-2018). Cairo: Department of Health Systems Development, World Health Organization Regional Office for the Eastern Mediterranean; 2018 (https://www.who.int/docs/default-source/primary-health-care-conference/phc-regional-report-eastern-mediterranean.pdf?sfvrsn=2a5a2528_2, accessed 3 July 2019).

8. Lohr KN, editor. Medicare: a strategy for quality assurance. Volume II: sources and methods. Washington (DC): National Academy Press;1990 (https://www.nap.edu/catalog/1548/medicare-a-strategy-for-quality-assurance-volume-ii-sources-and, accessed 8 October 2020).

9. Busse R, Klazinga N, Panteli D, Quentin W. Improving healthcare quality in Europe: characteristics, effectiveness and implementation of different strategies. Copenhagen: World Health Organization (acting as the host organization for, and secretariat of, the European Observatory on Health Systems and Policies) and OECD; 2019 (https://apps.who.int/iris/bitstream/hand le/10665/327356/9789289051750-eng.pdf?sequence=1\&isAllowed=y, accessed 8 October 2020).

10. Druce P, Bogatyreva E, Siem FF, Gates S, Kaade H, Sundby J, et al. Approaches to protect and maintain health care services in armed conflict - meeting SDGs 3 and 16. Confl Health. 2019;13:2. https://doi.org/10.1186/s13031-019-0186-0

11. WFP welcomes new funding pledge for humanitarian needs in Yemen from United Arab Emirates and Kingdom of Saudi Arabia. Cairo: World Food Programme; 2018 (https://www1.wfp.org/news/wfp-welcomes-new-funding-pledge-humanitarian-needs-yemen-united-arab-emirates-and-, accessed 6 June 2019).

12. Kruk ME, Gage AD, Arsenault C, Jordan K, Leslie HH, Roder-DeWan S, et al. High-quality health systems in the Sustainable Development Goals era: time for a revolution. Lancet Glob Health. 2018;6(11):e1196-e252. https://doi.org/10.1016/S2214109X(18)30386-3

13. Health emergencies. In: Annual report of the Regional Director 2018. Cairo: World Health Organization Regional Office for the Eastern Mediterranean; 2018 (http://www.emro.who.int/annual-report/2018/health-emergencies.html, accessed 10 June, 2019).

14. WHO grading of public health events and emergencies [Internet]. Geneva: World Health Organization; 2017 (https://www.who. int/emergencies/grading, accessed 22 May 2019).

15. Handbook for national quality policy and strategy. A practical approach for developing policy and strategy to improve quality of care. Geneva: World Health Organization; 2018:74 (https://www.who.int/servicedeliverysafety/areas/qhc/nqps_handbook/en/, accessed 13 June 2019).

16. Walugembe DR, Sibbald S, Le Ber MJ, Kothari A. Sustainability of public health interventions: where are the gaps? Health Res Policy Syst. 2019;17(1):8. https://doi.org/10.1186/s12961-018-0405-y

17. Fitter DL, Delson DB, Guillaume FD, Schaad AW, Moffett DB, Poncelet JL, et al. Applying a new framework for public health systems recovery following emergencies and disasters: the example of Haiti following a major earthquake and cholera outbreak. Am J Trop Med Hyg. 2017;97(4 Suppl):4-11. https://doi.org/10.4269/ajtmh.16-0862

18. Wagner Z, Heft-Neal S, Wise PH, Black RE, Burke M, Boerma T, et al. Women and children living in areas of armed conflict in Africa: a geospatial analysis of mortality and orphanhood. Lancet Glob Health. 2019;7(12):e1622-e31. https://doi.org/10.1016/S2214109X(19)30407-3

19. Urdal H, Che CP. War and gender inequalities in health: the impact of armed conflict on fertility and maternal mortality. Int Interactions. 2013;39(4):489-510. https://doi.org/10.1080/03050629.2013.805133

20. Nuzzo JB, Meyer D, Snyder M, Ravi SJ, Lapascu A, Souleles J, et al. What makes health systems resilient against infectious disease outbreaks and natural hazards? Results from a scoping review. BMC Public Health. 2019;19(1):1310. https://doi.org/10.1186/ s12889-019-7707-z

21. Kruk ME, Myers M, Varpilah ST, Dahn BT. What is a resilient health system? Lessons from Ebola. Lancet. 2015;385(9980):1910-2. https://doi.org/10.1016/So140-6736(15)60755-3 
22. Martineau T, McPake B, Theobald S, Raven J, Ensor T, Fustukian S, et al. Leaving no one behind: lessons on rebuilding health systems in conflict- and crisis-affected states. BMJ Glob Health. 2017;2(2):e000327. https://doi.org/10.1136/bmjgh-2017-000327

23. Pacifico Silva H, Lehoux P, Miller FA, Denis JL. Introducing responsible innovation in health: a policy-oriented framework. Health Res Policy Syst. 2018;16(1):90. https://doi.org/10.1186/s12961-018-0362-5

24. Handbook for national quality policy and strategy. A practical approach for developing policy and strategy to improve quality of care. Geneva: World Health Organization; 2018:13 (https://www.who.int/servicedeliverysafety/areas/qhc/nqps_handbook/en/, accessed 13 June 2019).

25. Institute of Medicine (US), Committee on Quality of Health Care in America. Six domains of health care quality. Crossing the quality chasm: a new health system for the 21st century. Washington (DC) National Academies Press; 2001.

26. Allen-Duck A, Robinson JC, Stewart MW. Healthcare quality: a concept analysis. Nurs Forum. 2017;52(4):377-86. https://doi. org/10.1111/nuf.12207

27. Eshaq AM, Fothan AM, Jensen EC, Khan TA, AlAmodi AA. Malnutrition in Yemen: an invisible crisis. Lancet. 2017;389(10064):312. https://doi.org/10.1016/So140-6736(16)32592-2

28. Aluttis C, Bishaw T, Frank MW. The workforce for health in a globalized context-global shortages and international migration. Glob Health Action. 2014;7:23611. https://doi.org/10.3402/gha.v7.23611

29. Bou-Karroum L, Daou KN, Nomier M, El Arnaout N, Fouad FM, El-Jardali F, et al. Health care workers in the setting of the "Arab Spring": a scoping review for the Lancet-AUB Commission on Syria. J Glob Health. 2019;9(1):010402. https://doi.org/10.7189/ jogh.09.010402

30. Bombard Y, Baker GR, Orlando E, Fancott C, Bhatia $P$, Casalino S, et al. Engaging patients to improve quality of care: a systematic review. Implement Sci. 2018;13(1):98. https://doi.org/10.1186/s13012-018-0784-Z

31. National Academies of Sciences, Engineering, and Medicine; Health and Medicine Division; Board on Health Sciences Policy; Forum on Medical and Public Health Preparedness for Disasters and Emergencies. Engaging the private-sector health care system in building capacity to respond to threats to the public's health and national security: proceedings of a workshop. Washington (DC): National Academies Press; 2018.

32. Wynn A, Moore KM. Integration of primary health care and public health during a public health emergency. Am J Public Health. 2012;102(11):e9-e12. https://doi.org/10.2105/AJPH.2012.300957

33. Khan Y, O'Sullivan T, Brown A, Tracey S, Gibson J, Genereux M, et al. Public health emergency preparedness: a framework to promote resilience. BMC Public Health. 2018;18(1):1344. https://doi.org/10.1186/s12889-018-6250-7

34. Boyd AT, Cookson ST, Anderson M, Bilukha OO, Brennan M, Handzel T, et al. Centers for Disease Control and Prevention public health response to humanitarian emergencies, 2007-2016. Emerg Infect Dis. 2017;23(13). https://doi.org/10.3201/eid2313.170473

35. Documet PI, McDonough BL, Van Nostrand E. Engaging stakeholders at every opportunity: the experience of the emergency law inventory. Am J Public Health. 2018;108(S5):S394-5. https://doi.org/10.2105/AJPH.2018.304615

36. Mowafi H. Conflict, displacement and health in the Middle East. Glob Public Health. 2011;6(5):472-87. https://doi.org/10.1080/174 41692.2011.570358 